\title{
Electric fences for reducing sheep losses to predators
}

\author{
ROGER D. NASS AND JOHN THEADE
}

\begin{abstract}
The use of anti-predator electric fences for reducing predation on sheep was investigated by interviewing 101 sheep producers in the Pacific Northwest. Significant reductions in sheep losses to predators were reported after installation of electric fences compared to pre-fence losses. Low sheep losses to predation were also reported by those producers that acquired sheep after installation of electric fences. The expenses of construction and maintenance were important considerations in management plans; however, most producers were satisfied with electric fences for sheep containment and predator exclusion.
\end{abstract}

\section{Key Words: sheep, predation, fencing}

Anti-predator electric fences may provide some producers with a reliable self-help method for reducing losses of sheep to coyotes and dogs. Details of construction, maintenance, costs, and some evaluation of this non-lethal control method have been reported (deCalesta and Cropsey 1978, deCalesta 1983, Gates et al. 1978, Henderson 1978, Linhart et al. 1982, Shelton 1984, Thompson 1979). Previously, most electric fences for excluding predators had not been in use long enough to provide an adequate data base for pre- and post-fence predation loss evaluations or assessments of long-term problems or benefits.

Recent animal husbandry surveys indicated that many farm flock sheep producers installed electric fences during the past 2 to 4 years. This survey was designed to collect data on efficacy of electric fences for reducing predation. This information may stimulate interest by other sheep producers in this method.

\section{Methods}

Electric fence users in California, Oregon, and Washington were interviewed during 1984-85 about their operational successes or failures for reduction of predation on sheep. Data were obtained for fence construction dates, area enclosed, area grazed, flock sizes, numbers of predator-killed sheep during pre- and postelectric fence periods, months of fence use per year, management

Authors are research biologist, Predator Research Station, P.O. Box 593, Twin Falls, Idaho 83303-0593; and biological technician, Predator Studies Branch, Denver Wildife Research Center, Animal and Plant Health Inspection Service, U.S. Department of Agriculture. This study was conducted under the guidance and support of the U.S. Fish and Wildlife Service, Department of the Interior. The Center transferred to the Animal and Plant Health Inspection Service (APHIS) on 3 March 1986.

The authors wish to thank R. Engeman, M. Fall, F. Knowlton, P. Savarie, and H. Tietjen, Denver Wildlife Research Center, APHIS, USDA, for critically reviewing this manuscript.

Manuscript accepted 9 February 1988. considerations, lethal control implications, and problems associated with electric fence use. Fences or portions of fence were checked for general condition and maintenance excluding those in areas remote from the interview site.

Mean numbers of predator-killed sheep per year were compared between pre- and post-electric fence production years for each producer. Comparisons were made for long-term (2-7 years) and for all producers with pre- and post-electric fence experience (1-7 years). Pre- and post-electric fence predator losses were evaluated by testing the null hypothesis of no differences at $P=0.05$. Data were also obtained on predat or-killed sheep for producers who had always used electric fences.

\section{Results}

Interviews were conducted with 101 livestock producers (Oregon 79, Washington 18, California 4) that were using electric fences. Of these, 51 had sheep before and after installing fences, 43 acquired sheep after erecting fences, and 7 used charged fences for livestock containment, but not predator exclusion.

Producers with pre- and post-electric fence experience enclosed a mean of 301 acres $(S E=87$, Range $=1-3840$ ) with electric fencing out of a mean 387 acres (SE $=99$, Range $=3-3840$ ) available for grazing. Fifty-three percent ( 27 of 51 ) enclosed their entire grazing areas and $47 \%$ ( 24 of 51 ) had additional grazing acreage outside charged fences. Mean flock size 1,036 head $(\mathrm{SE}=398$, Range $=$ $20-20,000)$ and 22 of the $51(43 \%)$ had 300 or fewer sheep. Electric fences were used for protection from predation a mean of $\mathbf{1 0 . 6}$ months (SE $=0.4$, Range $=2-12$ ) per year, and 46 of $51(90 \%)$ fences were judged to be in good repair. Five producers (10\%) lost no sheep to predators before using electric fences; however, significantly more, $28(55 \%)$, reported no losses to predators after installation of charged fences $\left(t_{s}=5.21, P=<0.01\right)$. Reported sheep losses to predators were significantly reduced after installation of electric fences for 46 producers with 2 or more years (long-term) of electric fence experience (Table 1). The null hypothesis of no difference between pre- and post-electric fence sheep losses to predators was rejected $(t=3.76, \mathrm{df}=45, P=<0.01)$, and the alternate hypothesis of a reduction in post-fence sheep losses was accepted. The percentage of predator-killed sheep declined from 3.9 (pre-fence) to 0.3 (post-fence).

Similar results were obtained for pre- and post-electric fence sheep losses to predators when including the 5 producers with 1 
Table 1. Predator-killed sheep numbers and years of data for pre-and post-electric fence use by 46 sheep producers with 2 or more seasons' experience with ant-predutor type electric fences.

\begin{tabular}{|c|c|c|c|c|c|}
\hline \multirow[b]{2}{*}{ Statistic } & \multicolumn{2}{|c|}{ Pre-electric fence } & \multicolumn{2}{|c|}{ Post-electric fence } & \multirow{2}{*}{$\begin{array}{l}\text { Difference between pre- } \\
\text { and post-electric fence } \\
\text { sheep loss to predation }\end{array}$} \\
\hline & $\begin{array}{l}\text { Sheep lost to } \\
\text { predators/year }\end{array}$ & $\begin{array}{l}\text { Years of } \\
\text { loss data }\end{array}$ & $\begin{array}{l}\text { Sheep lost to } \\
\text { predators/year }\end{array}$ & $\begin{array}{l}\text { Years of } \\
\text { loss data }\end{array}$ & \\
\hline $\mathbf{X}$ & 41 & 3.3 & 3.5 & 4.1 & 37.2 \\
\hline SE & 10.7 & 0.2 & 1.4 & 0.2 & 9.9 \\
\hline Range & $0-454$ & $1-7$ & $0-35$ & 2.7 & $0-424$ \\
\hline
\end{tabular}

year (short-term) of experience with electric fences $(t=4.46, \mathrm{df}=50$, $P=<0.01)$. The mean decrease in sheep losses to predators between the last year with conventional fences and the first year with electric fences was $36.2 \pm 15.9$ (95\% confidence limits) per producer. The percentage of predator-killed sheep declined from 4.3 before electric fence use to 0.7 after electric fences were used.

A reduction in the need for lethal control after installation of electric fences was reported by 38 of $51(75 \%)$ producers. Livestock management workloads decreased after fence installation for 32 of $51(67 \%)$ producers.

Producers with only post-electric fence experience enclosed a mean of 84 acres (SE $=16$, Range $=3-500)$ out of a mean of 159 acres ( $S E=32$, Range $=3-880$ ) available for grazing. Forty-two percent (18 of 43) enclosed their entire grazing areas. Mean flock size was 392 head (SE $=58$, Range $=19-1200)$ and $25(58 \%)$ had 300 or fewer sheep. Electric fences were used for protection a mean of 9.7 months $(\mathrm{SE}=0.4$, Range $=5-12$ ) per year and $35(81 \%)$ kept fences in good condition. These producers used electric fences for a mean of 4 years $(S E=0.3$, Range $=1-10)$. The mean annual loss to predators was $1(\mathrm{SE}=0.3$, Range $=0-12)$. Twenty-six $(60 \%)$ had not lost any sheep to predators. Eighteen (42\%) producers indicated that lethal control was necessary to complement their use of electric fences to reduce predation.

Four producers reported no problems with their electric fences; however, about $95 \%$ said electrical malfunction, (shorting out) was a chronic maintenance problem. Vegetation, limbs, bears, and deer frequently caused problems and coyotes or dogs sometimes entered pastures through washouts and gates. Most producers were satisfied with their fences even though expenses of construction and maintenance were cited as important liabilities.

\section{Discussion}

Data from sheep producers interviewed during this study indicated that electric fences were effective in minimizing predation on sheep. Reported reduction of losses between pre- and post-electric fence use and minimal losses of those with only post-electric fence experience indicate that electric fences can deter predation on sheep. Even the 6 producers with extreme losses $(X=62)$ the first year after using electric fences showed a $51 \%$ reduction in predation over the previous year when conventional fencing was used.
Four producers with severe predation problems had large flocks on large grazing areas. Potential for electrical malfunctions, physical damage, additional gates, more washouts, and predator ingress increase as fenced areas increase in size. Continuous maintenance and vegetative control were cited for proper fence operation and to insure that the sheep stay confined and that predators stay excluded.

Most producers agreed that electric fencing decreased the need for intense lethal control; however, they indicated that lethal control was still needed to prevent predators from entering fenced areas and to protect sheep that were grazing outside of protected pastures.

Costs of new electric fences are greater than for electrical modifications of existing conventional net wire fences. New, antipredator, electric fences are cheaper than net wire anti-predator fences (deCalesta and Cropsey 1978, Shelton 1984). DeCalesta (1983) calculated that 4 miles of fence, labor, maintenance, and interest cost $\$ 2,218$ per year over an estimated 20 -year life expectancy. If sheep were worth $\$ 60$, a producer must save 37 per year to justify fencing 640 acres. Most of the producers in this study had much smaller grazing areas and the average lamb price during July, 1987, was \$78.30/cwt (Idaho Agricultural Statistical Service 1987); therefore protection costs would be cheaper than shown above.

Anti-predator electric fences can reduce predation on sheep. An investment in this management tool should be explored by those farm flock producers with persistent predation problems.

\section{Literature Cited}

deCalesta, D.S. 1983. Building an electric antipredator fence. Pacific NW Ext. Bull. 225.

deCaleata, D.S., and M.G. Cropsey. 1978. Field test of a coyote-proof fence. Wild. Soc. Bull. 6:256-259.

Gates, N.L., J.E. Rjch, D.D. Godtel, and C.V. Hulet. 1978. Development and evaluation of anti-coyote electric fencing. J. Range Manage. 31:151-153.

Henderson, J. 1978. Electric fence installation. Fence industry. May 1978. Idaho Agricultural Statiatics Service. 1987. Agriculture in Idaho. Issue $15-87$.

Linhart, S.B., J.D. Roberts, and G.J. Dasch. 1982. Electric fencing reduces coyote predation on pastured sheep. J. Range Manage. 35:276-281.

Shelton, $M$. 1984. The use of conventional and electric fencing to reduce coyote predation on sheep and goats. Tex. Agr. Exp. Sta. MP-1556.

Thompson, B.C. 1979. Evaluation of wire fences for coyote control. J. Range Manage. 32:457-461. 